\title{
LAS TORRES DE LA CATEDRAL DE GUADALAJARA
}

\section{Por Manuel Romero de Terreros}

Al reseñar la Catedral de Guadalajara, don Diego Angulo, en su Historia del arte hispanoamericano, escribe que las primitivas torres remataban en "media naranja"; y reproduce un dibujo del año de 1689 , que se conserva en el Archivo de Indias de Sevilla y que las representa con el segundo cuerpo, al parecer de planta circular, con cubierta efectivamente semiesférica. Por otra parte, se sabe que coronaban estas cúpulas sendas estatuas, de piedra recubierta de lámina de plomo, de San Miguel, como Patrono de la ciudad, en la del norte, y de Santiago Apóstol, como Patrono del Reino de la Nueva Galicia, en la del sur.

En las Noticias geográficas y estadisticas del Departamento de Jalisco, del año de 1843, se dice que "las cúpulas de las dos torres fueron derribadas por el temblor de tierra de la madrugada del 31 de mayo de 1818, y posteriormente se les quitó su segundo cuerpo con la intención de darles una forma más sólida, en cuyo estado permanecen".

Efectivamente, durante varios años quedaron las torres únicamente con su primer cuerpo, como se ve en estampas y pinturas de la época.

No fue sino hasta el pontificado del obispo don Diego Aranda, en. la primera mitad del siglo xix, que se erigieron los actuales típicos remates, en forma de conos octagonales, que, incorrectos y todo, imparten sin embargo un sello tan especial a la hermosa ciudad de Occidente.

La descripción que de las torres hace el padre Luis del Refugio de Palacio, aunque seguramente no muy correcta desde el punto de vista arquitectónico, tiene tan pintoresco sabor, que no vacilamos en transcribirla:

"Las torres, dice el benemérito fraile franciscano, conservan un cuerpo que es el primitivo, ornado de pilastras y cornisas toscanas, con dos ventanas en arco para cada frente y sus antepechos de hierro sin adorno... Hoy, al cuerpo primero sigue un cubo, muertos los ángulos de la planta, con lucernas ovales apareadas en cada una de sus faces, flanqueadas de cuatro pináculos cada una, trasuntando las góticas, quier no lo sean éstas en sus detalles, revestidas de ladrillos vidriados, con aristas cubiertas de azulejos. Dos cruces griegas, que son bien grandes, perfectamente doradas y caladas, se posan en las cúspides. 
"Dícese que, comiendo el obispo Aranda, vio semejantes torres en un plato dibujadas; luego arregló con el arquitecto don Manuel Gómez Ibarra que así las trazase. $Y$ era lo más lógico. No hay cosa más puesta en razón en este Guadalajara, tan acosado de temblores; solas se equilibran por su misma forma y se sirven a sí mismas de puntales, aparte de ser todo el cono de leve piedra pómez."

En el informe que rindió el arquitecto Gómez Ibarra acerca de la construcción de estos remates, consta que comenzó la obra el 30. de julio de 1851 y la terminó el 15 de julio de 1854 con un costo de $\$ 39,521.03$.

Si es cierta la tradición que refiere el padre Palacio, la vajilla en que se servía al prelado era de aquella loza que, desde el siglo xviII, venían produciendo las fábricas inglesas, adornada con vistas de aldeas, castillos, catedrales, edificios públicos y demás, en color azul, rosa, verde o negro. Ahora bien, ¿cuál fue el plato que sirvió de modelo para las torres de la Catedral de Guadalajara?

En nuestra opinión, formaba parte de una de las vajillas de loza de Staffordshire, que fabricaron los hermanos John y William Ridway, de 1814 a 1830 , con diseños, al decir de un crítico, de buen dibujo y delicado color. Un platón de uno de estos servicios de mesa se exornaba con una vista, entre otros edificios, de la Iglesia de Santa María, en Oxford, en la que se distingue claramente la "aguja" del templo, con sus pináculos, que fueron quizás en lo que se inspiró Gómez Ibarra.

Sea de ello lo que fuere, lo cierto es que, por absurdas, estéticamente hablando, que resultaran las torres de la Catedral de Guadalajara, han adquirido ya carta de naturaleza en el Valle de Atemajac, de la misma manera que la igualmente absurda estructura, dizque gótica, que erigió Zeferino Gutiérrez al frente de la Parroquia de San Miguel de Allende (sugerida, a lo mejor, por otro plato ingles), ha llegado a constituir inconfundible característica de esa bella e histórica ciudad guanajuatense. 